\title{
Ricardo Palma: Poeta Depurador
}

Ricardo Palma (1833-1919) es, sin lugar a dudas, la máxima figura literaria del Perú decimonónico. Fiel a una de las consignas de su siglo, Palma es hombre polifacético: periodista en su paĩs; colaborador en revistas y periódicos tanto nacionales como extranjeros; oficial de la marina de guerra; filólogo, crítico e historiador; político de ideología liberal; diplomático $\mathrm{y}$, por último, como todos sabemos, hombre de letras. La originalidad de sus "tradiciones"1 es universalmente reconocida. Contamos con excelentes estudios de éstas ${ }^{2}$ a los que remito al interesado en esta vertiente de su obra.

Mi propósito en este artículo no es ahondar en las "tradiciones" sino más bien centrarme en la lírica de Palma para poner de relieve una característica del poeta poco conocida. Aludo a la sistemática supresión por parte de Palma de algunos de sus poemas, publicados en su juventud, y que no vuelven a imprimirse en ediciones posteriores. Para llegar a esta conclusión hemos cotejado las tres ediciones de sus poesǐas: la de París (1865); Lima (1877) y Barcelona (1911).

Las primeras poesías de Palma salen a luz en 1855 bajo el nombre de Manuel R. Palma. Esta obra primeriza, Juvenilia (1850-1860), refleja la tónica del romanticismo imperante a la sazón en el Perú. Los jóvenes poetas limeños se nutren de la lectura de los románticos europeos: Vǐctor Hugo; Lamartine; Lord Byron, entre otros, y muy especialmente de los españoles Zorrilla; Tassara y Espronceda. Por aquellos años Palma preside las veladas literarias de Clorinda Matto y Juana Manuela Gorriti a la vez que, junto con toda una pléyade de bardos peruanos como Carlos Augusto Salaverry, Arnaldo Márquez, Clemente Althaus, Luis B. Cisneros y Pedro Paz Soldán, difunde la estética romántica a lo largo y ancho de su paìs. 
En su amenǐsimo libro, La bohemia de mi tiempo, Palma nos deja un testimonio directo de la actividad literaria de aquella época.

Los avatares políticos de la nueva república traen consigo la inestabilidad de los gobiernos, en su mayoria militares, y con frecuencia acarrean el destierro de los que militan en el bando perdedor. Palma, correligionario del partido liberal, se ve forzado a salir hacia el destierro en noviembre de 1860 , al ser derrotado éste en una de las innumerables revoluciones de esos años. Se dirige a Chile, donde pasa a colaborar en La Revista del Pacífico y La Revista de Sud-América. La producción poética de su exilio en Chile (1860-1862) la recoge en un volumen titulado Armonias. Libro de un desterrado (Parǐs, 1865).

$\mathrm{Su}$ trayectoria lírica continúa en Pasionarias (1865-1870); Verbos y Gerundios (1870-1878); Nieblas (1880-1906) y Filigranas (1890-1908). ${ }^{3}$ No es éste el momento de estudiar la totalidad de su obra como poeta. ${ }^{4}$ Lo que nos interesa es documentar el aserto de que Palma omite deliberadamente muchos de sus poemas juveniles en las ediciones de sus Poesias completas. Como botón de muestra, valga el que reproducimos a continuación, publicado por primera y única vez en La Revista de Lima en 1863 (tomo II, pp. 731-740). ${ }^{5}$

\section{NO HAY TRAMPA CON EL DEMONIO \\ (Leyenda popular) \\ Dedicatoria a Clorinda}

Ello al fin no es más que un cuento

De aquellos que oí en la infancia,

Esa edad cuya fragancia

Se ha evaporado en el viento.

Oyelo, niña gentil,

Tú por cuya frente pura

Aun no de la desventura

Cruza la nube sutil.

Te acaricia con sus alas

$\mathrm{El}$ angel de la inocencia,

$\mathrm{Y}$ es aurora tu existencia

Rica de esplendor y galas;

$Y$ por eso tu candor

Despierta mi poesía

$\mathrm{Y}$ busca nueva armonía

El harpa del trovador. 
Si con lo raro se arroba,

Paloma, tu pensamiento

$\mathrm{Y}$ una bruja por el viento

Montada en caña de escoba;

Y el diablo que con sus piés

San Miguel hace tortilla,

Causan á tu alma sencilla

Un misterioso interés;

Sé de cierto, vida mia,

Que gozarás doblemente

Con la historia que hoy te cuente

Humilde mi fantasia.

$Y$ pues no te es importuna

Mi voz, serafín bendito,

Vas á escuchar la que he escrito

En una noche de luna.

I

Promedia el siglo dieziocho

Y de la orgullosa España

El escudo soberano

En Lima espléndido se alza.

Refieren que era de Octubre

Una lluviosa mañana

Cuando un hombre recatándose

En una modesta capa,

Atravesó la Alameda,

Llegó al cerro de las Ramas,

Y bajándose el embozo,

Con misteriosas palabras

$Y$ entrecortado el acento

Tres veces al diablo llama.

Ya que el embozo ha arrojado

El que por los cerros anda,

Lector, sin ser importunos

Podemos verle la cara;

Aunque hay caras en el mundo

Tan repugnantes y estrañas, 
Que estar debieran cubiertas

Eternamente con máscara. $\mathrm{Y}$ á fé, que entre tales rostros $\mathrm{El}$ de nuestro héroe se halla Mostrando por corto apéndice Que en los ocho lustros raya.

El diablo debió andar listo Allá en los tiempos de marras, Porque acudió presuroso Ante tan torpe demanda; $Y$ hoy vemos todos los días Que abundan hombres tan mandrias. Que llaman una legión

De diablos y ni uno se alza

Cuando en los tiempos antiguos Con llamar uno bastaba.

Presente ya Satanás, Según lo narra la fama, Entre él y el desesperado La conversación se entabla - ¿Qué me quieres? -Un contrato

-Ya te escucho y ... ¡vamos! ... habla Que me urje el tiempo y no quiero Desperdiciarlo en palabras - Amo una muger; mas ella Constante mi amor desaira -Será tuya ¿y qué me ofreces De mi ayuda soberana En cambio? -Si á amarme llega, Satanás, son tuyos mi alma Y mi cuerpo ... ¡Oh! Sỉ ... proteje

A quien tu poder acata.

Lo miró el diablo sonriendo; Mas luego tras breve pausa Le dijo, fingiendo el aire De aquel que de otro se apiada. -El trato es trato: aquí firma $Y$ en mi protección aguarda; Aunque alma como la tuya No es para mí mucha ganga 
II

Sacó el diablo un pergamino,

Escribió en él el contrato

Con las fórmulas precisas

Para semejantes casos;

$\mathrm{Y}$ al acabar el escrito

Estampó su garabato,

Que al fin el diablo es jefe

De todos los escribanos

$\mathrm{Y}$ documento que él fragua

No hay medio de desatarlo.

El otro firmó-Se dieron

Los contratantes la mano.

Convirtióse el diablo en humo,

Y el otro paso entre paso

Volvió á la ciudad, y cuentan

Que se le miró con pasmo

Tornado desde ese día

En un mancebo gallardo,

Rico, elegante, travieso

$Y$ de las damas mimado,

Solo continuó tan bestia

Como ántes de su contrato,

Que al cabo génio y talento

No son cosas que dá el diablo.

\section{III}

-Madre ¿qué será que ayer

Cuando de misa salǐ,

Se fijó un jóven en mí

Mirándome con placer

Y yo ... yo me sonreí?

Y me llamó entonces flor,

Dulce espíritu de amor,

Perla luciente y estrella,

$Y$ dijo que era más bella

Que un serafín del Señor.

$\mathrm{Y}$ has de saber jay de mï!

Que al escuchar esas cosas 
Yo no sé lo que sentí. . .

$\mathrm{Y}$ en mis manos temblorosas

Puso un clavel carmesí.

Después la noche llegó

Y el infeliz la pasó

Parado al pié de mis rejas

Diciendo sentidas quejas...

$Y$ abrï la ventana yo.

Me contó un cuento de amores

Con tan hermosos colores

Que ... ¿lo creerás, madre mía?

Toda yo me estremecía

A sus écos seductores.

Después, á la luz incierta

Del alba se fué el doncel.

Y... madre! fuerza es te advierta

Que si en él pensé despierta

Dormida soñé con él.

Luego al resplandor del día

Alcé mi plegaria pìa...

Pronuncié el nombre de Dios ...

$Y$ otro nombre dijo en pos

Fascinada el alma mía.

¿Qué será, dí la impresión

Que por vez primera siento?

¿Por qué es que en todo momento

El está en mi corazón,

El está en mi pensamiento?

Una hermosa mañana

De aquellas perfumadas y tranquilas

Que tiene Lima, esplén dida sultana

De la costa del Sur, una doncella

Más que los sueños de la infancia bella

Reflejando en la luz de sus pupilas

La sencillez de su alma enamorada,

Así a la madre de su amor decia:

-Perdóname si lo amo, madre mía,

Y el corazón me exalta su mirada. 
Pobre niña inocente!

¿Por qué no has aprendido

A sofocar el ìntimo latido

Del corazón ardiente?

Triste de tî! que ignoras

En tus febriles horas

Que es la vida la farsa más completa;

Que á todo hombre un papel el Increado

En ella ha señalado

$Y$ que abundan los rostros con careta.

IV

Corrieron dias y la hermosa Elena Abandonó su hogar. Como el infante Con un juguete su ambición vé llena, Para ella el mundo se encerró en su amante.

Madre, homor, cuento existe de querido Al corazón de la muger aun pura, Sacrificó al amor de un fementido Soñando un cielo en su infantil ternura.

Todo tiene un magnífico destello

Si por el prisma del amor se mira...

El cielo es más azul .. ¡Ay! Es tan bello

Sentir otra alma que de amor suspira!

Es tan bello el amor! No hay armonia Más dulce que la voz del ser amado!

La vida es un raudal de poesía!

Sublime el porvenir! Grato el pasado!

V

Pobre Elena! Era tu espíritu

Como solitaria flor

Cuyo cáliz perfumaba

El tibio aliento de Dios.

A los embates del mundo

Te abandonó un seductor,

Como hoja que de su tallo

Arrancára el aquilon.

El destruyó tu pureza,

El destruyó tu candor, 
$Y$ las fibras en pedazos

Te rompió del corazón.

Mugeres! En vuestras almas

Hay todo un mundo de amor

De entusiasmo y de ternura,

$\mathrm{Y}$ de fé y abgenación.

Vosotras, las que aprendisteis

En la escuela del dolor,

Las que apurais el veneno

Que deja la seducción,

Llorad, llorad por Elena

Pobre mártir del amor!

Murió Elena al encontrarse

Perdida y sin compasión

Abandonada del hombre

Que el sosiego la robó.

¿Acaso será un delito

En la muger el amor?

Para qué la puso el cielo

Dentro el pecho un corazón?

Murió! como muere el lírio

Agostado en su verdor

Cuando le falta el rocio

La brisa y el arrebol.

Era el amor para el alma

De la niña, un bien mayor

Que el agua para el sediento

Y que para el ciego el sol.

Mugeres! Si habeis sentido

La tristissima emoción

Que siempre trae el recuerdo

De un amor que nor burló

Llorad, llorad por Elena

Pobre mártir del amor!

Niña gentil á quien cuento

El misterio tentador,

Cuando sientas en tu pecho

El fuego de la pasión;

Cuando la edad te permita

Apreciar lo que escribo hoy; 
Ten compasión por Elena

Que si en la falta cayó

Lloró tanto, que su falta

La purificó el dolor.

Murió de pena, alma mía,

Que hay tan profunda aflixion

En ver huir la ventura

Que el llanto pierde su voz,

$\mathrm{Y}$ el alma tiene dolores

Que solo consuela Dios.

Tortolilla de ojos dulces!

Huye de la seducción

$Y$ cuando estés en los días

De la juventud veloz

Llora, llora por Elena

Pobre mártir del amor!

\section{VI}

Lector, si algun paseo

Que imposible no creo

En los Descalzos diste, habrás notado

Que cerca de la huerta

Hay tapiada una puerta

Con una cruz. Yo siempre fuí tentado

Del diablo aquel que llaman curioso,

Y echéme á averiguar como un ocioso

El como y el por qué la enseña santa

Allì del cristianismo se levanta.

Cuenta el pueblo muy formal

Que un hombre llegó al Covento,

Habló al guardian un momento

$\mathrm{Y}$ á poco vistió el sayal.

Tanta era su contricción

$\mathrm{Y}$ tanta su caridad

Que conquistó en la ciudad

Del santo reputación.

$\mathrm{Y}$ aunque no faltó tunante

Que esclamase á boca llena

-Ese hombre sedujo á Elena-

Dijo al mundo- ¡Calumniante! 
Si ha usado de seducción

Hoy es monge y eso bastaY el santo hábito que gasta Mata la murmuración.

Mas cada noche entretanto Que nuestro monge pasaba, El claustro se alborotaba Con sus quejas y su llanto $Y$ por la celda corría Hasta perder el sentido Diciendo á grito tendido Que el malo lo perseguía.

Lo cierto es, que al fin un día Fué al guardián el penitente $Y$ dijole francamente Que á consultarle venía.

No anduvo el guardián reacio $\mathrm{Y}$, según dice la crónica, No fué consulta lacónica Que hablaron un largo espacio.

$\mathrm{Y}$ sin muchos requilorios Te diré, caro lector, Que él contó los que en rigor $\mathrm{Y}$ a te son hechos notorios.

El pacto con Lucifer Y la seducción cobarde, Y que abandonó más tarde Deshonrada á una muger. Y dijo, anegado en lloro, Que una mano negra, humeante Iba siempre de él delante Ya en la celda, ya en el coro.

\section{VII}

A la mañana siguiente Los frailes todos salieron En procesión por el claustro Del espacioso convento, 
Y el ceremonial sagrado

Iba triste precediendo

El penitente, á quien guia

Invisible para el resto

De acompañantes la mano

De aquel arcángel protervo.

Pasaron un claustro y otro

Y se detuvo el cortejo

Ante una puerta que abrióse

Como por raro misterio

De alguna mano invisible

Bajo el impulso violento.

Pero su dintel apenas

Traspuso con paso incierto

El penitente, la puerta

A cerrar volvióse luego

Filtrando por ella estraño

Olor de azufre y de infierno.

Esparcióse la noticia

La misma tarde en el pueblo

De que se llevó el demonio

Un deudor en alma y cuerpo;

Por que es acreedor el diablo

Tan inflexible y severo

Que cuando cobra no admite

Ni dilación ni tropiezo.

Escrito en su juventud, este poema de Palma evidencia el uso de la fantasía y un acusado romanticismo, con posible influencia del Fausto de Goethe y el Don Alvaro de Angel de Saavedra. Muchos de los poemas igualmente eliminados de sus Poesias completas se resienten de este mismo tipo de trasfondo. Cabe preguntarnos qué motivó a Palma para suprimirlos de sus ediciones posteriores. Pienso que la clave nos la proporciona el propio Palma en el prefacio a sus Poesias completas de 1911, cuando declara aludiendo a esta producción de su primera etapa poética:

Avéngome hoy á reimprimir esos tres libritos que fueron como mi iniciación en la vida de las letras y en el romanticismo que, por entonces, se había adueñado de los espíritus 
juveniles. ¡Ah! los románticos de 1845 á 1860, en América, fuimos verdaderos neuróticos por lo revesado y contradictorio de nuestros ideales, reflejados en versos, ora henchidos de misticismo ampuloso y de candor pueril, ora rebosando duda cruel ó desesperanza abrumadora. 6

Parecería, pues, como si Palma, en su senectud, se arrepintiese del fervor romántico de sus años juveniles. Esto explicaría la decisión de Palma de omitir muchas de estas composiciones a la hora de preparar la última edición de sus obras poéticas, edición ésta que dista mucho de ser, como reza el título, completa.

University of California,

CARLOS GARCÍA BARRÓN Santa Barbara

\section{NOTAS}

1. José de la Riva Agüero apunta en este sentido: "El puesto de Palma en la posteridad parece ya fijado. Representante del criollismo, y quizá por eso con un fondo español muy claro y definido, no es de los que quedarán relegados a la historia literaria. Todo induce a creer que nuestros nietos lo leerán con igual asiduidad y cariño que nosotros. Sus Tradiciones ganarán con la distancia: se harán más interesantes y poéticas, porque se referirán a costumbres cada vez más lejanas; y las generaciones que no alcancen ni una sombra del Perú antiguo, vendrán a aprender lo que fué de los labios de este conversador entretenido y sabrosisimo, que mezcla a las remembranzas siempre melancólicas de las pasadas épocas un dejo burlón y risueño, y una pïcara y decidida predilección por la crónica escandalosa y los cuentos subidos de punto, que lo hacen muy interesante y atractivo." Obras completas (Lima: Pontificia Universidad Católica del Perú, 1962), tomo I, 203.

2. Ver Alberto Tauro del Pino, Ricardo Palma. Tradiciones peruanas (Lima: Imprenta de la Universidad Nacional Mayor de San Marcos, 1969).

3. Augusto Tamayo Vargas, Literatura peruana (Lima: Imprenta Iberia, s.f.), tomo II, p. 650 .

4. Me parece reveladora la declaración que hace el propio Palma refiriéndose a sí mismo como poeta: "Todo el cariño literario que abrigo por mis Tradiciones ó leyendas en prosa, sólo puede igualarse al desapego que siento por mis renglones rimados. Si en los dǐas de la mocedad pudo el amor propio alucinarme hasta el punto de creerme poeta, hoy, en horas de desencanto senil y de razonamiento frío, apenas si me tengo por mediano versificador." Preámbulo de Palma a sus Poesías completas (Barcelona: Editorial Maucci, 1911), p. 5. Recomiendo la lectura del libro de Guillermo Feliú Cruz, En torno de Ricardo Palma. La estancia en Chile (Valparaiso: Imprenta de la Universidad de Chile, 1933).

5. Debe aclararse que Palma fue el director de esta valiosa revista peruana durante la primera época de la misma. Véase mi trabajo, "La Revista de Líma", de próxima publicación en el Bulletin of Hispanic Studies.

6. Poesías completas, p. 6. 